\title{
Characteristics and Structure of Hopeite-Mineral (Type A3(PO4)2.4H2O)
}

\author{
Aji Syailendra Ubaidillah ${ }^{1}$, Lutfian Rusdi Daryono ${ }^{2 *}$, Arifudin Idrus ${ }^{3}$, I Wayan Warmada ${ }^{4}$, \\ Karsten Knorr ${ }^{5}$
}

${ }^{1}$ Department of Geological Engineering, Gadjah Mada Universitas, Indonesia; Depatment of Mining Engineering, Universitas Muhammadiyah Mataram, Indonesia.

${ }^{2}$ Lab. Biotechnology for Resources, Division of Sustainable Resources, Graduate School of Engineering, Hokkaido University, Japan.

\author{
${ }^{3}$ Department of Geological Engineering, Gadjah Mada Universitas, Indonesia \\ ${ }^{4}$ Department of Geological Engineering, Gadjah Mada Universitas, Indonesia \\ ${ }^{5}$ Hahn Meitner Institute, Berlin
}

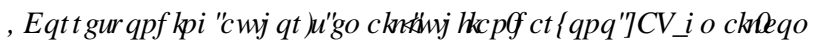

\begin{abstract}
The aim of the study was to gain more information about the structural changes during the dewatering reactions of the above compounds. The paper is focus on the low-temperature absorption of hopeite clay mineral, afterward the phases are examined for the dependence of temperature at different pressures. Hopeite shows signs of a phase transformation. Their use for the dental cement industry as a lubricant for cold-rolling mills is to be emphasized, such as coating with phosphate mineral or carbonaceous crystal. This is shown by the appearance of the new reflexes. The observed changes take place below the dewatering known from the literature. The phase change was investigated using a neutron scattering experiment. A temperature-pressure phase diagram of the dewatering could be set up in the range of $275 \mathrm{~K}$ to $380 \mathrm{~K}$ and 10-3 mBar to $103 \mathrm{mBar}$ with the temperature-dependent powder diffiactometer at different pressures and the temperature-dependent neutron scattering experiment. In this work, it has been proved that the dewatering of the hopeite is dependent on pressure and that the dewatering process of the hopeite is a reversible process.
\end{abstract}

Keywords - Phase transformation, temperature-dependent powder diffractometer at different pressures, temperaturedependent neutron scattering, phosphate coating, clay mineral.

\section{INTRODUCTION}

The chemical classification of the minerals is based on the mineralogical tables of Strunz $(1957,1978)$ in 9 classes. The phosphate mineral class, which also contains arsenates and vanadates, is particularly rich in arsenic due to its diadochi (mutual replacement of the individual ions). The phosphates consist of compounds which can be derived from the phosphoric acid H3PO4. The structures are predominantly determined by PO4 tetrahedra and are mostly watercontaining. The water-free phosphates include apatite (Ca5[OH, F, Cl] [PO4]3), pyromorphite ( $\mathrm{Pb} 5[\mathrm{Cl} \mid \mathrm{PO} 4) 3]$, amblygonite (LiAl[F|PO4]) and lazulite ((Mg, $\mathrm{Fe}) \mathrm{Al} 2[\mathrm{OH} \mid \mathrm{PO} 4] 2)$.

Hopeite belongs to the water-containing phosphates. These minerals can be assigned to the general formula with $\mathrm{A} 3(\mathrm{PO} 4) 2.4 \mathrm{H} 2 \mathrm{O}$. A is mainly a divalent cation, such as $\mathrm{Zn}, \mathrm{Fe}, \mathrm{Co}, \mathrm{Cu}$ and $\mathrm{Ca}$, for $\mathrm{n}$ there are characteristic values from 0 to 10 .

The aim of the study was to gain more information about the structural changes during the dewatering reactions of the above compounds. Here the phases are investigated as a function of temperature at different pressures. Hopiete shows signs of a phase transformation. This is expressed by the appearance of the new reflexes. The observed dewatering takes place below the dewatering known from the literature (Hopeite's first dewatering takes place at about $100^{\circ} \mathrm{C}$, the second dewatering at about $200^{\circ} \mathrm{C}$ (Shchegrov LN, 1986). The cause of the phase transformations was investigated by a neutron scattering experiment. The research conducted at the Hahn Meitner Institut Berlin.

In the automotive industry, Hopeite is an important material. They are grown to act as a layer protector on the body of the car of corrosion (Yoshihara and Okita, 1983). Hopeite is also used as a dental cement and as a lubricant for steel production in cold rolling mills. 


\section{MATERIAL AND METHODS}

The measurements were performed on a Guinier Low Temperature Diffractometer G645 Huber. The Guinier diffractometer offers a relatively high resolution due to it focusing layout. The device is equipped with a closed helium cryostat CTI Cryogenic Model 22C. The Guinier Low Temperature Diffractometer G645 is designed for the temperature range from $10 \mathrm{~K}$ to $350 \mathrm{~K}$ and angle range from $0 \mathrm{o}$ to $50 \mathrm{o}$ Theta. The freezing of the cooling systems is avoided by a vacuum. The vacuum was controlled by adjusting the vacuum valves. The negative pressure could be varied from 10-3 mbar to room pressure. The full-pattern analysis method of Rietveld programs, Foolproof, Hill (1992) was used to analyze the Roentgen data. The sample comes from Hagendorf-Süd Bayern, Germany. The syntheses were conducted at Technische Universität Berlin.

\section{RESULTS}

According to Whitker (1975), the orthorhombic hopeite ( $\mathrm{Zn} 3(\mathrm{PO} 4) 2.4 \mathrm{H} 2 \mathrm{O})$ has the space group Pnma with the lattice constants $\mathrm{a}=10.629 \AA, \mathrm{b}=18.333 \AA, \mathrm{c}=5.040 \AA$. Thermodiffractograms from Hopeite were recorded between $270 \mathrm{~K}$ and $335 \mathrm{~K}$ in $2 \mathrm{~K}$ steps of $2 \mathrm{o}-20 \mathrm{o}$ Theta and a vacuum pressure of $10-3 \mathrm{mbar}$. The appearance of new reflexes and the disappearance of reflexes of orthorhombic hopeite indicate a phase transformation (Figure 1).

Roentgen imaging has shown that phase transformations takes place. The critical temperatures of the phase transformations under vacuum pressure of $10-3 \mathrm{mbar}$ (here starting at $273 \mathrm{~K}$ and finished at $288.1 \mathrm{~K}$ ) do not corresponds to that from the literature value. The trend of the d-value of the reflex (020) between the temperature from $270 \mathrm{~K}$ to 350 $\mathrm{K}$ shows that in the initial phase the crystal behaves normally, the lattice expands with the rising temperature (Figure 2). The relationship of the spacing $\mathrm{d}$ between adjacent (hkl) and the lattice plane parameters $\mathrm{a}, \mathrm{b}, \mathrm{c}, \alpha, \beta, \mathrm{\gamma}$ is in an orthorhombic axis system is:

for the reflex (020) is also:

$$
\frac{1}{d_{h k l}}=\frac{h^{2}}{a^{2}}+\frac{k^{2}}{b^{2}}+\frac{l^{2}}{c^{2}}
$$

$$
b=2 d_{020}
$$

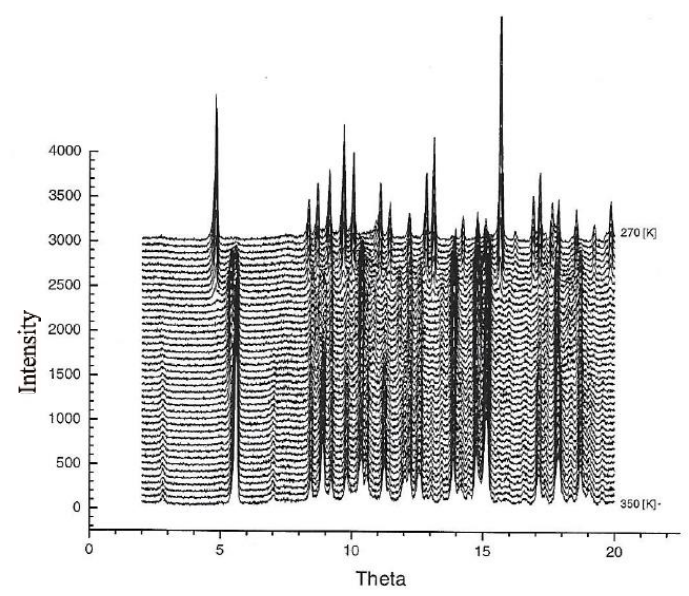

Figure 1. Thermodiffractograms of Hopeit between $270 \mathrm{~K}$ and $335 \mathrm{~K}$ steps of $2^{\circ}-20^{\circ}$ theta and vacuum pressure of $10^{-3}$ mbar.

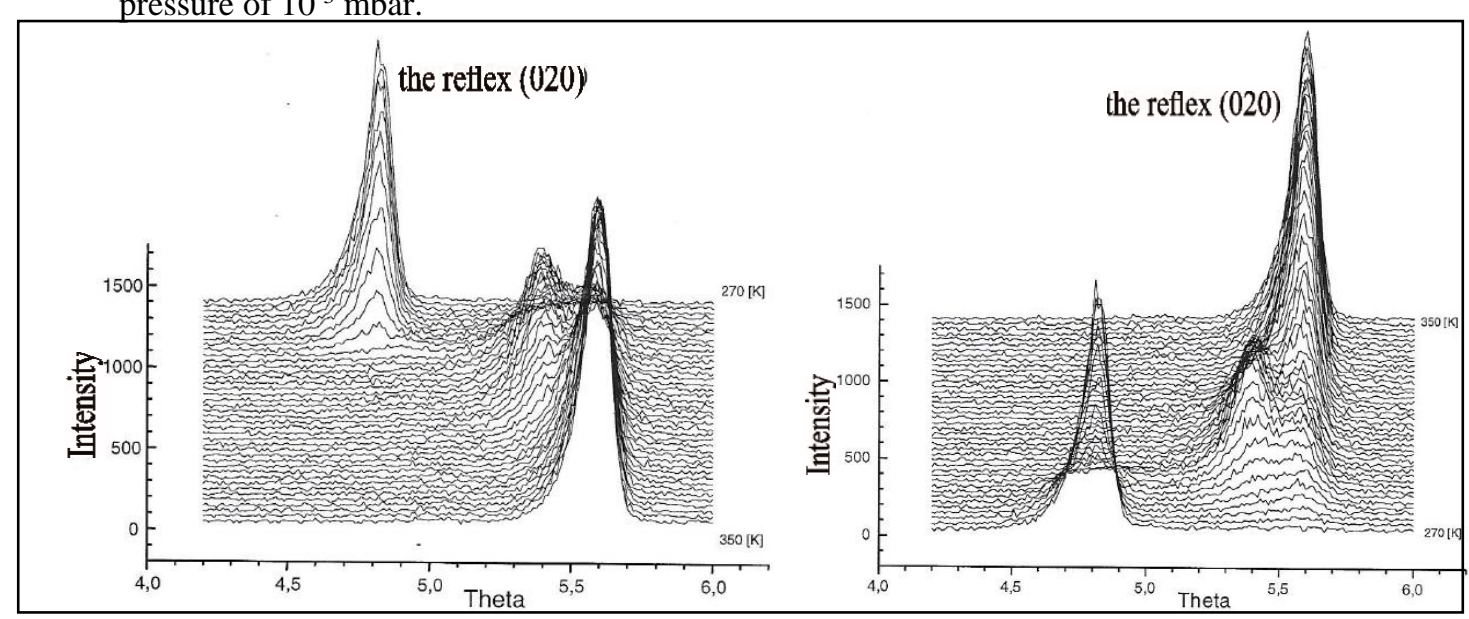

Figure 2. The Trend of the reflex (020) between $350 \mathrm{~K}$ and $270 \mathrm{~K}$ in $2 \mathrm{~K}$ steps from $4.2^{\circ}$ to $6^{\circ}$ Theta and at a pressure of $10^{-3}$ mbar. 


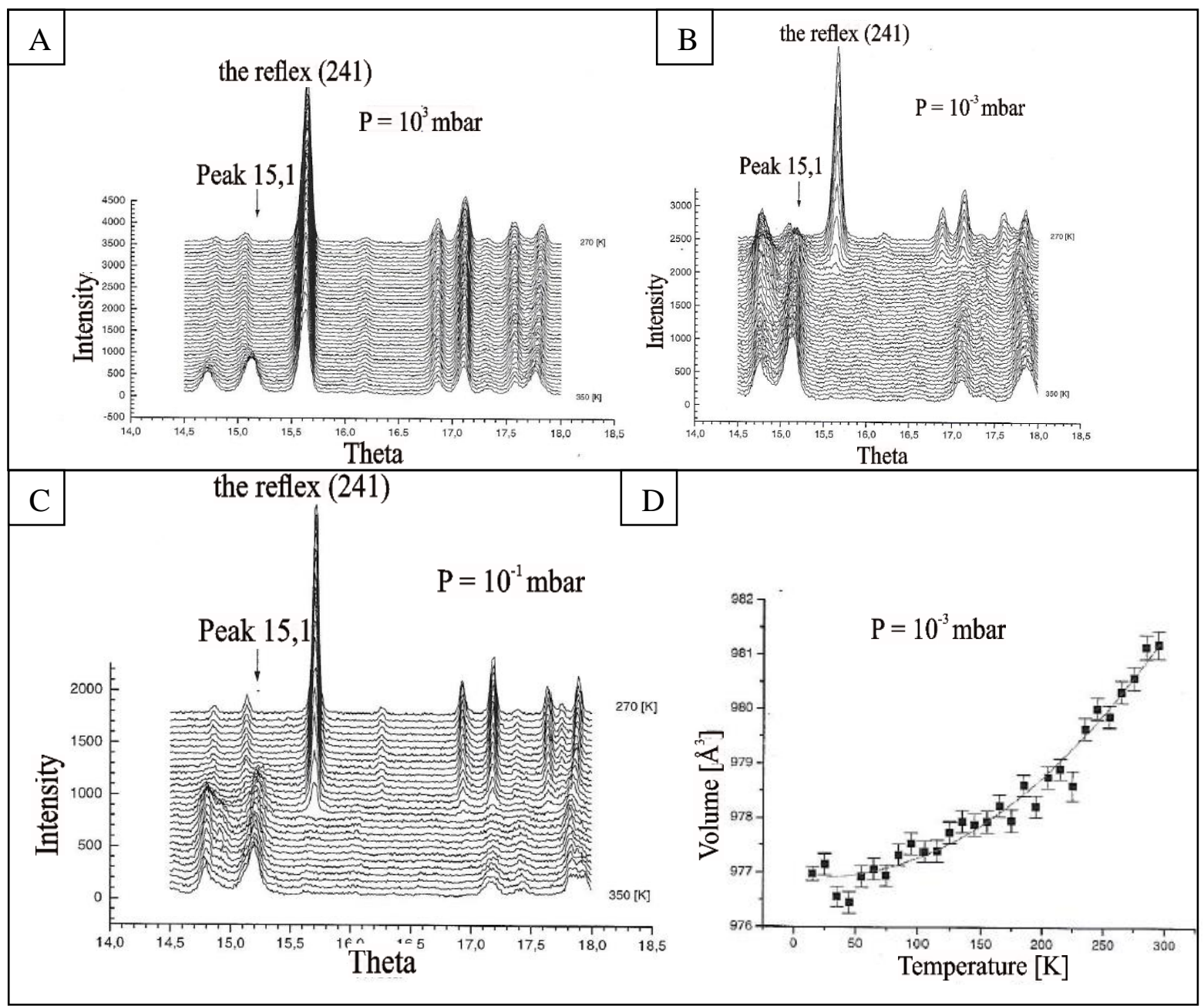

Figure 3. A, B, C : Thermal diffractogram of hopeite between $270 \mathrm{~K}$ and $350 \mathrm{~K}$ in $3 \mathrm{~K}$ steps at Theta range from $14.5^{\circ}$ to $18^{\circ}$ with $10^{3} \mathrm{mbar}, 10^{-3} \mathrm{mbar}$, and $10^{-1} \mathrm{mbar}$ Pressure. And D : Volume of hopeite depending on the temperature between $15 \mathrm{~K}$ and $295 \mathrm{~K}$ in $10 \mathrm{~K}$ steps at a pressure of $10^{-3}$ mbar.

\section{DISCUSSION}

The Thermodiffractogram results were confirmed by a temperature-dependent neutron scattering experiment at a pressure of 4.5 mbar. Here, on the one side, the structural changes can be observed and on the other side, the water loss can be determined by the decrease of the incoherent scatter contribution. From the results of the neutron scattering experiment that the transformation at about $300 \mathrm{~K}$ and the pressure at about 4.5 mbar (Figure 4 ) are connected with the dewatering, it follows that the dewatering of hopeite is dependent on the vacuum at low temperatures.

\section{CONCLUSIONS}

It is affirmed in the process of the study that the transformation of hopeite is very sensitive towards to low pressure. Measurements with different negative pressures showed, on the one side, that the starting and ending temperatures of the dewatering decrease with increasing negative pressure, and on the other side, the coexistence field from completely to intermediary hydrated hopeite becomes smaller. The summarization of the results for the dewatering temperatures of hopeite shows Fig.5.

By logarithmic application of the pressure, a linear relationship with temperature can be assumed. The slope of the start and the end of the dewatering is different; at higher temperatures, the range of transitions between tetra- and dihydrate hopeit is larger. 


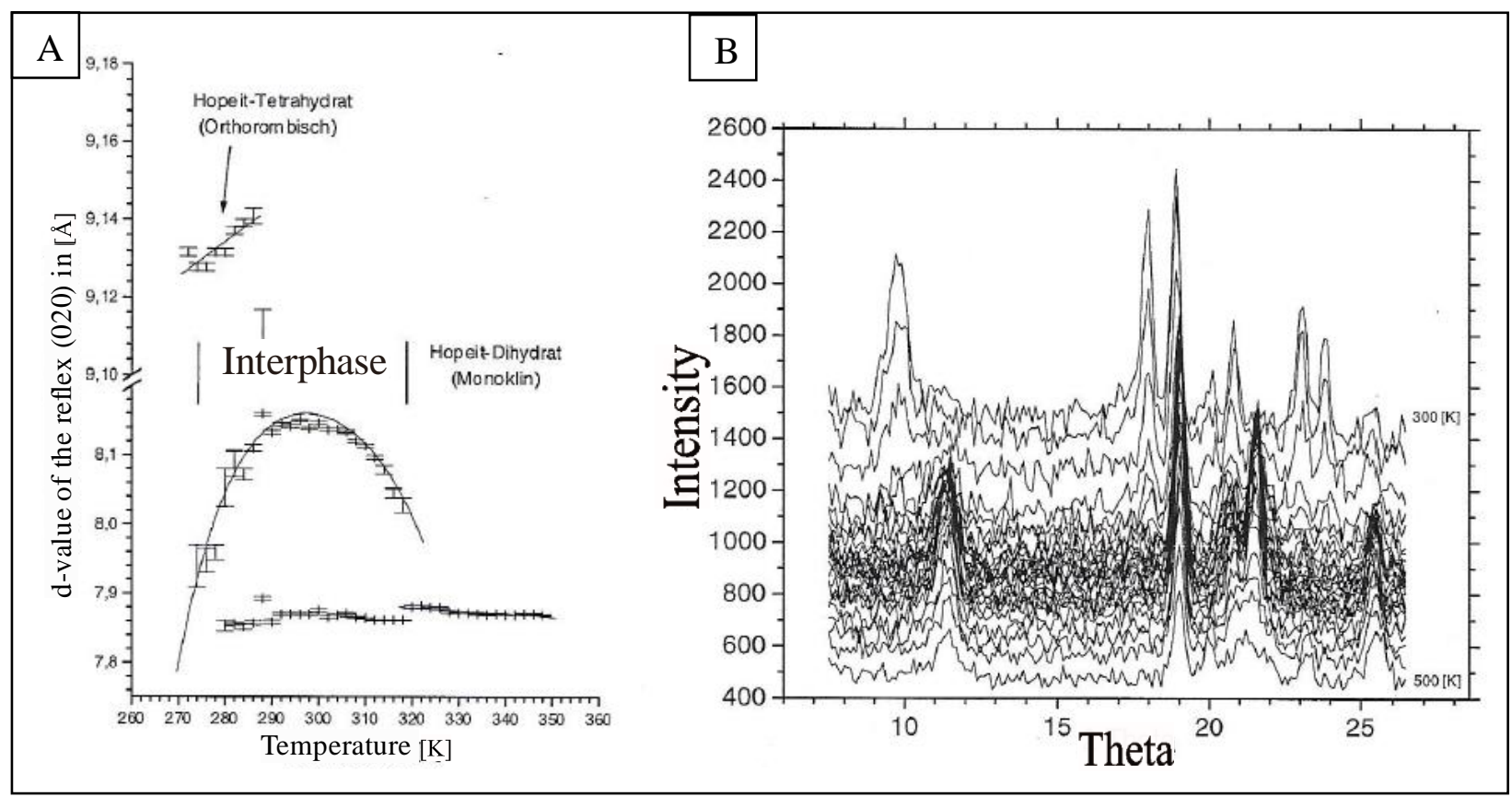

Figure 4. A: The d-values of the reflex (020) over the temperature of 270 to $350 \mathrm{~K}$ at $10^{-3}$ mbar. And B: Thermodiffractograms of the neutrons scattering experiments of hopeite between $300 \mathrm{~K}$ and $500 \mathrm{~K}$ in $5 \mathrm{~K}$ steps at a pressure of 4.5 mbar.

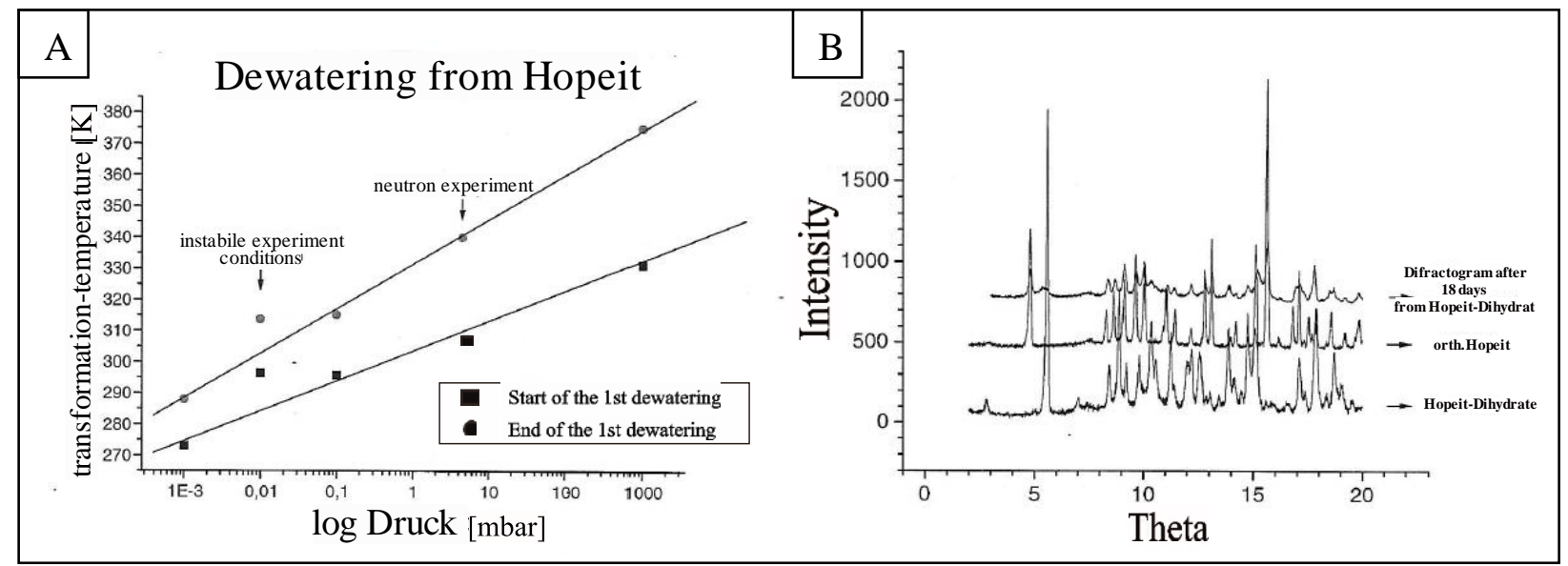

Figure 5. A: Graphical presentation of the transformation temperature of the hopeit as a function of pressure. B: Comparison-Diagram of the same sample between an orthorombic-Hopeit and the dihydrat-Hopeit and the Hopeit after 18 days.

\section{ACKNOWLEDGEMENT}

The authors for this paper would like to thank you for the opportunity to make this work for all the institute members and the responsible persons.

\section{REFERENCES}

[1] Calvo C. (1963), The Crystal Structure of $\gamma$ - Zn3(PO4)2, Phys. Chem. Solids, 24, 141.

[2] Calvo C. (1965), The Crystal Structure of $r$ - Zn3(PO4)2, Can. J. Chem. 43, 436.

[3] Hill R.J. and Jones J.B (1976), The Crystal Structure of Hopeit, Am. Mineral., 61, 987-995.

[4] JCPDS - PC - PDF von ICDD, International Center of Diffraktion Data, Version 2.14.

[5] Kleber. Bautch. Bohm (1990). Einführung in die Kristallographie, 17.Aufl., Verlag Technik Berlin. München.

[6] Liebau F. (1962), Über die Struktur des Hopeits, Chem. D. Erde, 22, 430. 
[7] Mamedow, C.S. Gamidow, R.G, und Below N.W. (1961), Crystal Structure of Hopeit, Zn3(PO4)2.4H2O, Kristallogr. 6, 144 (russ).

[8] Rietveld R.M. (1967), Line Profile of Neutron Powder Diffraction Peaks for Structure Refinement, Acta Cryst. 22, 155-152.

[9] Shchegrov L.N. (1986), Thermolylis of Orthorombic Hopeit, Zn3(PO4)2.4H2O, Ukrainian Agricultural Acadeny. Translated from Izvestya Academy Nauk SSSR, Neorganeski Materialy, vol. 22, No.1, PP.157159, Original Article Submitted May 29th, 1984.

[10] Stephens J.S., and Calvo C. (1967), The Crystal Structure of $\beta$ - Zn3(PO4)2, Can. J. Chem. 45, 2303.

[11] Touloukian Y.s., Kirby R.K., Taylor R.E., Lee T.Y.R.(1975), Thermal Expansion Metallic Elements and Alloy (1975), Vol.13 of ThermoPhysical Properties of Mater, pp.154-162, New York Washington.

[12] Wolve C.W.(1940), Clasification of Minerals of The Type A3(XO4)2.nH2O, Amer. Miner., 25,787.

[13] Whitker A. (1975), The Crystal Structure Of Hopeit, Zn3(PO4)2.4H2O, Acta Cryst. B31, 2026.

[14] Wilson A.J.C. (1992), International Tables Of Crystalofraphie, (Mathematical, Physical and Chemical Tables), Volume C. 